\title{
Retraction Note
}

Retraction note to: Synthesis and Biological Evaluation of Entecavir 4'-Ester Derivatives

FENG Deri, LIU Jiaan, LIANG Shuang, WANG Yanyan and XU Youjun*

School of Pharmaceutical Engineering, Shenyang Pharmaceutical University, Shenyang 110016, P. R. China

(C) Jilin University, the Editorial Department of Chemical Research in Chinese Universities and Springer-Verlag GmbH 2014

Retraction to: Chem. Res. Chin. Univ.

doi: 10.1007/s40242-014-4183-y

This article is retracted because the corresponding author XU Youjun was put as the corresponding author without knowing anything before its publication. All were arranged by the first author, Mr. FENG Deri, in abnormal ways. Hence all other authors and $\mathrm{XU}$ state here that this paper has no relation with other authors and with Xu's working university. XU also states that he has never used “xuyoujun65@163.com”as corresponding author contact email.

Therefore XU declares that the paper should be withdrawn from the journal as soon as possible in case any negative effects on other authors and on this journal.

The online version of the original article can be found at http://dx.doi.org/10.1007/s40242-014-4183-y.

*Corresponding author. E-mail: xuyoujun@syphu.edu.cn

(C) Jilin University, The Editorial Department of Chemical Research in Chinese Universities and Springer-Verlag GmbH 2015 